\title{
Editorial: What Shall I Cry?
}

No Bombay duck is a duck, but some anecdotal evidence is evidence. Some of it is good evidence. We have been hearing mutually supportive reports that enrolment into philosophy courses is increasing in a good many universities, colleges and polytechnics. Why should this be so, when the air is thick with outcries about the importance and value of an education in science or mathematics or engineering or law or medicine, all supported by promises of economic benefit to the kingdom, and-to reapply a phrase from an earlier epoch-of 'positions of considerable emolument' for the individual recruits? Many of the philosophy lecturers who bring the news are puzzled by the phenomenon, which is more surprising still to those who are shouting the outcries. Yet if one thinks about the matter, as a philosopher properly should, it becomes intelligible and even predictable. The purpose of the shouting is to increase the proportion of students who take scientific and vocational courses. It is understandable enough that considerable numbers of young people should be influenced by the appeals and arguments to which they are subjected. Among them, ex hypothesi, are some who would probably have read different subjects if they had not been influenced by the climate of opinion. It is natural, again, that some of these, having been influenced by persuasions whose content was extraneous to the individual interests and preferences that ought properly to determine such a question, will fall by the wayside, finding that their chosen studies do not grip them as firmly as they had expected. We have all known numbers of students who have changed course, away from the subjects for which their A levels had prepared them. When they wish to return to the humanities and arts end of the spectrum they find their choices restricted by the scope of their A level studies. Not even the highest grades in physics, chemistry and mathematics will pave a path to linguistic or literary subjects, to history, geography or modern languages, classics or oriental studies. They must turn to fields where advanced study requires no previous experience. And so they turn to archaeology or the social sciences, to theology or law-or to philosophy.

By contrast, yet contributing to a single overall picture, there are young people of independent mind in whom the propaganda for 'useful' subjects evokes a reaction towards the humanities at the sixth form stage, so that they take A levels in arts subjects and then wish to read 'non-school' subjects such as law or philosophy. Something should be done about it. Somebody should do something about it. Perhaps so. 


\section{Editorial: What Shall I Cry?}

But it does not follow that there is anybody in particular who should do something about it. Even when the point is expressed in terms of what the country needs there is no identifiable individual whose duty it is to meet the need. And certainly no individual students, exercising the freedom of choice without which any system of education would be a fraud, should be rebuked or maligned because they pursue what they are interested in rather than what somebody else feels that they should be interested in. An agent who is not a free agent is not an agent. 